\title{
Growth and Unemployment: towards a theoretical integration
}

\author{
Fabio R. Aricò \\ Department of Economics and Quantitative Methods \\ University of Pavia - Via San Felice, 5 - 27100 Pavia - Italy \\ Fax +39-0382-304226 \\ f.arico@unipv.it
}

September 2001

\begin{abstract}
We observe in the literature of the past decade some innovative contributions identified a relation between economic growth and long run unemployment. This set of contributions is composed of very few elements, all characterized by a high degree of heterogeneity about their features and about their final results.

In the first part of the survey we provide a classification of these early contributions. In the second part we explore some alternative formulations of the problem and we present a wider set of models displaying interesting features, able to promote further studies about the persistence of unemployment in a growing economy.
\end{abstract}

Keywords: growth, unemployment, job-search, human capital, strategic complementarities, co-ordination failure.

JEL classification: E24, J21, J64, O41.

\section{Introduction}

Economic growth and Labour economics have been regarded so far as two separate fields of investigation, dealing with different issues and developed with different tools. In spite of this general statement it recently seems that a theoretical integration between growth and unemployment might be considered something possible and even desirable.

The revolution of Endogenous growth theory, started at the end of the ' 80 s, has not yet exhausted its potentialities in producing new contributions. Departing from the Solow-Ramsey paradigm this process of diffusion generated a heterogeneous set of models. These models allowed to produce a fertile ground to grow new ideas and to develop new tools for the economic analysis.

A similar story can be told about developments in Labour economics. The debates amongst Monetarist and Keynesian views of unemployment, as well as new contributions of Lucas' approach and the New Keynesian Economics, have generally assumed a static perspective in respect of the productive capacity of the system. It is obvious that, under this assumption, there was no point to account for growth in a model of unemployment. A significant innovation occurred with Pissarides' (1990) formulation of an unemployment theory in equilibrium. He formalized in a unique framework many previous attempts to study the labour market in a dynamic perspective, providing useful tools to analyse both long run and short run unemployment. Pissarides also introduced a first link between 
long run unemployment and growth (see Pissarides (1990), Ch. II), matching his model with the neoclassical framework of economic growth. The main result founded by Pissarides is a positive correlation between growth and unemployment based on a "capitalization effect." When the labour market is not frictionless this effect relies on the fact that firms are much more willing to invest in new vacancies during the period of high growth.

An alternative view was suggested by Aghion's and Howitt's (1994). They presented a model based on the Schumpeterian idea of "creative destruction," to show that the relation among growth and unemployment is actually much more complex than in Pissarides' framework. Their general statement claims that, because of the interplay of competing effects, the sign of the relation between growth and unemployment can be either positive or negative. Their model consistently predicts that high rates of growth are negatively correlated with unemployment, while low rates of growth are positively correlated with unemployment.

In a different contribution, based on strategical interaction among the agents, Acemoglu (1997) suggests a third way to explain the presence of unemployment in a model of technological change, which relies on the concept of strategic complementarities and co-ordination failure.

The literature about growth and unemployment formalized in a dynamic general equilibrium environment is still based on very few contributions. This just seems to be the very beginning of an interesting and important debate. The persistence of unemployment as a long run phenomenon still represents (especially for European countries) a core issue that needs to be solved through a convincing explanation and an opportune set of remedies. Actually the urge for further studies is self-evident.

This survey means to present the most important contributions about the presence of unemployment in a growing economy, suggesting further alternative and possible explanations for this phenomenon. For this reason the article can be ideally divided in two parts. In the first part we will introduce the recent literature about the topic of growth and unemployment, which will be summarized in Section II. In the second part we will provide a classification of some early contributions in the field of Growth theory, which seem able to generate a fertile ground for further research. In Section III we will focus on the characteristics of the labour supply and on the heterogeneous distribution of skills among different workers. In Section $I V$ we will stress the relevance of complementarities of factors, processes and strategies as a possible cause of unemployment. The main results and observations will be summarized in Sections $V$. 


\section{Technological change, growth and unemployment}

The research about the topic of growth and unemployment took place in the middle of the last century, thanks to the seminal works of Harrod (1939) and Domar (1947). These were important but isolated contributions in growth theory since they have not been followed by any relevant debate in literature. The affirmation of Solow's (1956) model and of its Ramsey-CassKoopmans formulation was based, in spite of earlier descriptions of the growth process, on substitutability among factors, flexible coefficients of the production function and inelastic supply of inputs. These core assumptions of the neoclassical paradigm led growth theorists to focus on models based on a balanced path with efficient allocation of resources.

Technological progress was introduced as exogenous variable and the steady state of the model was often determined independently in respect to the degree of "embodiment" of technological progress. This fact displaced any interest regarding any form of heterogeneity inside the economy, allowing to build aggregate models without loss of generality.

These common features clarify the reason why long run unemployment was totally ruled out by neoclassical growth models, which have represented for a long period the leading, if not unique, tool to investigate economic expansion.

For the reasons explained above the literature about growth and unemployment is new and not extensive. After almost fifty years it seems that the issues raised by the Harrod-Domar model returned back to the economists' attention. The introduction of dynamic tools for the analysis of the labour market and the diffusion of the Endogenous growth research programme represented two basic steps that allowed establishing a first link between these two fields.

At the end of the 1980s Endogenous growth models started to develop increasing interest about the specific features of the cumulative factors, showing that the steady state may be not unique, neither efficient. In the same time Labour economics abandoned its static, short run perspective, in order to re-define concepts and tools apt to investigate the persistence of unemployment in the long run. The concurring effects of these two processes generated a fertile ground to develop further studies about the presence of unemployment in a growing economy, starting a process which is just at the very beginning, but that displays high potentialities for producing more fruitful results in the future.

We can identify two main sets of contributions about the topic of growth and unemployment. In the first set the issue is developed devoting much more attention to the institutional contest of the economy, building models that are definitely more policy-oriented. In the second set of contributions we observe models that are more specifically concerned with technological processes and with the interplay of multiple heterogeneous factors. In our opinion these models 
are still characterized by a descriptive attitude, rather than suggestions about the policymaking. On the other side, they are better micro-founded and flexible for developing further studies.

Belonging to the first set of contributions we remark on the work by Gordon (1995), who meant to provide a common explanation to the productivity slowdown and high employment of the US and the relatively high growth, high employment of European countries. Gordon claims that the trade-off between growth and unemployment may occur in the short run, generated by structural shocks, like wage shocks. The trade-off disappears in the long run, through to a process of dynamic adjustment.

Another famous contribution dealing with the effect of fiscal policy in a growing economy was provided by Daveri and Tabellini (2000). The authors present a theoretical model supported by a wide set of empirical evidence, apt to investigate the relation between growth, unemployment and taxation in the industrialized countries. Daveri and Tabellini claim that if the wage-setting mechanism is affected by any form of rigidities, such as the presence of a monopolistic union, the role of fiscal policy is determinant for the identification of a trade off between growth and unemployment. The main idea relies on the fact that, when wages are protected by a monopolistic union, taxing labour income determines an increase in the real wage rate. An increase in the cost of labour gives incentive to firms to substitute capital for labour, lowering the marginal productivity of capital. That displaces investments, thus slowing down economic growth. The empirical evidence provided by Daveri and Tabellini shows that the tax-effect on the level of unemployment can be permanent even when the effect on the wage rate is just temporary.

In another interesting contribution, Cahuc and Michel (1996) investigate the role of minimum wage in a model of endogenous growth. Like Daveri and Tabellini (2000) they develop a model of overlapping generations. In their model the labour force is composed of a group of skilled workers and a group of unskilled workers. The technology displays constant return to scale and it is influenced by the presence of a social externality generated by the process of human capital accumulation, following Lucas (1988). The presence of a minimum wage, usually identified as one of the causes of unemployment, plays an important role in this model, determining a high relative demand for skilled labour. Since a higher relative price for unskilled labour increases the demand for skilled labour, rational workers find an incentive to invest in human capital in order to avoid unemployment. This enhances the positive effect of the social externality, supporting both growth and employment. 
As a last example we report the presence in literature of a contribution by Van Schaick and De Groot (1998). The authors match growth and unemployment through a re-interpretation of the

Solow's condition in a model of endogenous growth with efficiency-wages ${ }^{\square}$. The modified version of the Solow's condition interprets the level of labour efficiency as the result of R\&D activities performed in a high-tech sector, determining a link between the invention activity and the unemployment equilibrium determined on the labour market.

In all the previous examples the role of the institutions is determinant to identify the link between economic expansion and the labour market. We will now turn to the second set of models of growth and unemployment. Removing all of the considerations concerned with the structure of taxation and the rigidity of wages, it is in our intention to show that one can still identify many other different links between growth and unemployment. These links are intimately related with the characteristics of the accumulation process and with the strategic behaviour of the agents. We will focus our attention in deeper detail about these issues.

We will depart from the theory of job-search, developed by Pissarides (1990) in his seminal work, and we will subsequently consider some of the developments and contributions that followed this approach, which is the closest to the neoclassical tradition. We will then analyse the neo-Schumpeterian approach of Aghion and Howitt (1994) and their attempt to provide some micro-foundations of labour market dynamics, related with the effect of creative destruction emerging from the invention process. We will finally consider a third approach by Acemoglu (1997), which will be completely based on the strategic interaction of firms and workers.

\subsection{Pissarides and the job-search theory}

\section{The basic framework}

The seminal work by Charles Pissarides (1990) represents a first and complete collection of job-search models ${ }^{\text {[ }}$. Chapter II of his book is completely dedicated to job-search and growth and consists of one of the first attempts to explain the presence of unemployment in a growing economy. The model adopted is an extension of the Neoclassical growth model with exogenous technological progress. At this first stage there is no aim to endogenize changes in technology.

\footnotetext{
${ }^{1}$ For an introduction about the literature on efficiency-wages consider in example: Stiglitz (1976), Shapiro and Stiglitz (1984), Akerlof and Yellen (1986).

${ }^{2}$ See also Pissarides (2000). The new edition presents some developments about the basic issues introduced in Pissarides (1990) and collects an extensive bibliography of the most recent works related with job-search.
} 
Search-theory assumes that activity on the labour market is uncoordinated, time-consuming and costly. A proper matching function represents the result of this activity as the number of matches in function of the number $U=u N$ of unemployed workers and the number $V=v N$ of vacancies available in the economy at a certain point in time.

$$
m N=m(u N, v N)
$$

The function $m$ is concave, homogeneous of degree one and increasing in both arguments. Concavity is assumed in order to represent a congestion externality that takes place in the labour market. The more vacancies opened by the firms, the shorter the search-effort of unemployed workers; the more unemployed workers on-search in the labour market, the faster match available for each firm. Stated that $\theta=v / u$, we can express: $q(\theta)=m(u N, v N) / v N=m(v / u, 1)$ as the rate of recruitment by the firms.

Workers' flows move out of and into unemployment. Job-specific shocks occur according with a Poisson process of rate $\lambda$ and determine the end of a match with a firm. We can write the dynamic evolution of unemployment in the following form:

$$
\dot{u}=\lambda(1-u)-\theta q(\theta) u
$$

On the right side of equation [2.1.2] the first term represents the flow of workers into unemployment and the second term the flow of workers out of unemployment. In steady state we can express the rate of unemployment in function of the parameter $\lambda$ and of the labour market tightness $\theta$.

$$
u=\lambda /[\lambda+\theta q(\theta)]
$$

Equation [2.1.3] is the Beveridge-curve, usually represented as a convex to the origin and downward-sloping relation on the $(U, V)$ space of the labour market.

Pissarides assumes that firms produce the final good using capital and labour through a costant return to scale (CRS) technology, concave and increasing in both factors:

$$
y_{i}=F\left(K_{i}, A L_{i}\right)
$$

Equation [2.1.4] can be expressed in its intensive form: $y=f(k)$. We assume at first that each firm can open only one vacancy. The firm engages a research activity for matching his vacancy with a worker affording a hiring cost per unit of labour denoted by $z$. When the vacancy is matched, the firm rents capital at rate $r$ and produces output $y$. Firms evaluate the presentdiscounted revenue of a vacant job $W$ and the present discounted revenue of a matched job $J$, in order to satisfy the Bellman equation:

$$
r W=-z+q(\theta)(J-W)
$$

On the left side it expressed the capital cost, where $r$ indicates the interest rate. On the right side the value of the rate of return is obtained by summing the hiring cost and the expected net 
revenue in the occurrence of a job match. In equilibrium there are no rents for vacant jobs, so that if $W=0$ :

$$
J=z / q(\theta)
$$

The "job-creation equation" [2.1.6], expresses that the profit belonging to a new job is equal to the expected cost of hiring a worker. A similar evaluation is performed for each matched job, by using the Bellman equation:

$$
r(J+k)=f(k)-\delta k-w-\lambda J
$$

The left side represents the asset value of a matched vacancy plus the value of rented capital. The right side expresses the profit emerging from a filled job, where $w$ is the cost of labour and $\delta$ is the rate of depreciation of capital.

Substituting equation [2.1.6] in equation [2.1.7] we obtain that ${ }^{\text {[ }}$.

$$
f(k)-(r+\delta)-w-\frac{(r+\lambda) z}{q(\theta)}=0
$$

In order to derive a complete specification of the steady state, a description of the wage-setting mechanism is required. Pissarides observes that in a labour market described as an uncoordinated and costly activity, the sum of expected returns of a searching firm and expected returns of a searching worker is strictly inferior to the returns emerging from a job match. There is presence of rents generated by each matched job that are to be shared between profits and wages. The solution suggested is the adoption of a Nash-bargain mechanism, which leads to the following result:

$$
w=\pi z+(1-\pi)[f(k)-(r+\delta) k+\theta z]
$$

The equilibrium wage equation expressed in [2.1.9] is the solution of the bargaining problem. It results to be a weighted average between the benefit for unemployment $b$ and the marginal productivity of labour, augmented of the average hiring cost $\theta z$. Parameter $\pi$ indicates the profit share. The congestion externality in the labour market displays its linear effects on the equilibrium wage through parameter $\theta$. Equations [2.1.3], [2.1.8], [2.1.9] determine the steady state configuration for $(u, \theta, w)$.

This basic model can now be extended in order to obtain exogenous growth.

Exogenous disembodied technological progress can occur, assuming that the productivity parameter $A$ in equation [2.1.4] increases over the time and for all the firms in a classical labour-augmenting fashion.

$$
A_{t}=A_{0} e^{-\gamma}
$$


Each firm can now open a wider number of vacancies, denoted by $V_{i}$. It is assumed that the number of firms is large enough to eliminate uncertainty about labour flows. The wage setting mechanism follows the same Nash-bargaining mechanism described by equation [2.1.9]. This assumption about wage-setting mechanism is consistent with results if a market for capital does exist and there are no long-term contracts. In fact each firm decides how many jobs are to be created by anticipating the correct wage, but the same firm assumes the wage as given when the number of jobs is actually stated. The stream of firm $i$ ' s expected profits is expressed by:

$$
\Pi_{i}=\int_{0}^{\infty} e^{-r t}\left[F\left(K_{i}, A L_{i}\right)-w L_{i}-z A V_{i}-\dot{K}_{i}-\delta K_{i}\right] d t
$$

The dynamics of the labour force for each firm is described by:

$$
\dot{L}_{i}=q(\theta) V_{i}-\lambda L_{i}
$$

Profits are maximized in respect to capital and number of vacancies opened, subject to the constraint expressed by [2.1.12]. For given paths of $A$ and $\theta$, Euler's conditions guarantee the existence of an optimal path for $K_{i}$ and $L_{i}$. The steady state is obtained setting to zero equation [2.1.12], when:

$$
V_{i}=\frac{\lambda L_{i}}{q(\theta)}
$$

To obtain consistency in steady state, we assume that the unemployment benefit $b$ and the hiring cost $z$ are both indexed with the level of wages: $b=b_{0} w, z=z_{0} w$. The new wage-equation turns into the following expression:

$$
w=\frac{1-\pi}{1-\pi z_{0}-(1-\pi) b_{0} \theta} A[f(k)-(r+\delta) k]
$$

Solving the intertemporal optimisation problem for equation [2.1.12], conditions for the steady state are derived. As long as $F\left(K_{i}, A L_{i}\right)$ is homogeneous of degree one can express these conditions in terms of units of efficient labour, through the use of the intensive form:

$$
\begin{aligned}
& f^{\prime}(k)=r+\delta \\
& A\left[f(k)-k f^{\prime}(k)\right]=w+\frac{(r+\lambda-\gamma)}{q(\theta)} z_{0} w
\end{aligned}
$$

The marginal productivity of labour equals the wage paid to the workers, plus a term which accounts for the frictions of the labour market. Substituting equation [2.1.16] in equation [2.1.14] we identify a final condition for the labour market tightness $\theta$ :

\footnotetext{
${ }^{3}$ Equation [2.1.8] can be regarded as a labour demand relation, which is downward sloping in the space $(w, \theta)$, even when the productivity of labour is constant.
} 


$$
\bar{\pi} b_{0}-(1-\bar{\pi}) z_{0} \theta-\frac{r+\lambda-\gamma}{q(\theta)}(1-\bar{\pi}) z_{0}=0
$$

From equation [2.1.17] we find that $\gamma$ and $\theta$ are, ceteris paribus, positively related. That is due to the dynamics which lie behind the firm's profit maximization process. Considering Euler's conditions for maximizing equation [2.1.11] it can be shown that each firm is supposed to afford hiring costs today for the stream of profits it will earn tomorrow. We assumed that profits and hiring costs both grow at the same rate in steady state so, with higher growth rates, firms will find rational to open more vacancies today in order to save hiring costs of tomorrow, thus obtaining an increase in the stream of profits. This identifies the "capitalization effect" which is based on the forward-looking behaviour of firms that are supposed to maximize their profits. A change in the rate of growth determines a change in the optimal choice of firms about the number of vacancies to be opened, reflecting its effects on the labour market.

The model still lacks the means to determine the rate of interest, which is identified by the demand-side of the economy. Pissarides follows a traditional dynamic IS-LM approach. The law of accumulation of capital is defined from:

$$
\dot{K}_{t}=Y_{t}-\delta K_{t}-C_{t}
$$

The aggregate consumption is defined as a fixed amount $\beta$ of the disposable income:

$$
C_{t}=\beta\left(Y_{t}-\delta K_{t}+(\mu-\dot{p}) M_{t} / P_{t}\right)
$$

Where: $\mu$ is the rate of growth for money, $\dot{p}$ is the rate of inflation and $M / P$ expresses the real balances. The LM balance condition closes the model:

$$
M_{t} / P_{t}=g(r+\dot{p}) Y_{t} \quad g^{\prime}<0
$$

From the demand-side set of equation one can derive the following steady-state condition:

$$
[1-\beta-\beta \gamma g(r+\mu-\gamma)] f(k)-[(1-\beta) \delta+\gamma] k=0 \quad[2.1 .21]
$$

Equation [2.1.21], together with equation [2.1.15], determines $r$ and $k$ in steady-state.

We have already observed that the rate of growth is negatively related with the rate of unemployment from the supply side's perspective. From equation [2.1.21] we note that an increase in the growth rate lowers the capital ratio per unit of efficient labour, determining an increase in the rate of interest $r$. Through equation [2.1.17] this affects the labour market tightness and the effect can be either positive or negative, depending on the sign of the difference $r-\gamma$. While the supply-side of the model determines a univocal relation among growth and unemployment, the final effect can be either positive or negative when one considers the demand-side dynamics. 


\section{Endogenous consumer's behaviour}

Pissarides (1990) defines the aggregate consumption as a fixed amount of disposable income. Eriksson (1997) presents a slightly different version of the model, developing the demand-side on the line of the Ramsey-model. This modification can turn into an interesting tool to investigate the feedback impact generated by the labour market on the rate of growth of the economy. Assuming that each consumer displays a constant intertemporal elasticity of substitution (CIES) instantaneous utility function:

$$
U_{j}=\left(C_{j}^{1-\sigma}-1\right) / 1-\sigma
$$

The household's budget constraint is defined by:

$$
\dot{K}_{j}=(1-\tau) r K_{j}+w(1-u) L_{j}+b_{o} w u L_{j}-C_{j}+V I_{j}
$$

Households are all identical. Each household accounts for the time spent in production $(1-u) L_{j}$ and the time spent in unemployment $u L_{j}$ as well as it needs to consider the rental income derived from putting out vacancies $V I_{j}$. The parameter $\tau$ represents the tax rate on capital income.

Re-expressing the consumption in unit of efficient labour and solving the intertemporal optimisation problem for the households one finds that:

$$
\dot{c}=\sigma^{-1}\left(f^{\prime}(k)-\rho-\sigma \gamma\right) c
$$

From equations [2.1.15], [2.2.24] and [2.2.23], expressed in efficiency units, one can determine the responsiveness of $k, c$ and the new endogenous variable $r$ in respect of the parameters of the model. The rate of interest becomes positively varying in respect of the tax rate $\tau$, the elasticity of substitution $\sigma$, the rate of intertemporal substitution $\rho$ and of the rate of growth $\gamma$.

Computing the effect of a variation of the growth rate on the market tightness and of a variation of the market tightness on unemployment, Eriksson determines a positive relation between growth and unemployment, under the assumption that the elasticity of intertemporal substitution is small enough. Technically, Eriksson showed that $d r / d \gamma=\sigma /(1-\tau)$, so that if $\sigma<1$ $\tau$, then an increase in $\gamma$ decreases the difference $(r-\gamma)$. From equation [2.1.17] this turns into a lower level of the market tightness and a subsequent increase in unemployment. Since all the parameters of the model display a positive relation with the rate of interest, one can even focus on the demand side of the model, concluding that if either $\sigma$ or $\rho$ increase, the rate of interest increases, stressing the trade-off between growth and unemployment.

Eriksson shows how an apparently slight change of the original model determines an opposite result in respect to what was obtained by Pissarides (1990). Endogenizing the rate of interest 
allows to explore in detail the interplay of the labour market with the mechanics of growth. The rate of interest assumes a key role in Eriksson's specification of the model. Every kind of intervention which is meant to lower the rate of interest determines higher employment.

A similar result is obtained when the rate of growth is endogenously determined by some cumulative factor which sustains the fall of the productivity of capital in equation [2.2.24]. The rate of growth becomes much more responsive to a change of the parameters, and the trade-off between growth and unemployment can be still identified .

\section{Endogenous growth and unemployment: Neoclassical and Keynesian features}

Bean and Pissarides (1993) presented further developments of the basic model of job-search. They built an overlapping generation model where both growth and unemployment are endogenous variables: this allows us to analyse another kind of feedback effect that unemployment generates on growth. Their framework is based on an extension of the basic overlapping generation model by Diamond (1965), where they introduce a technology which displays decreasing returns to capital at the firm level, but constant returns at the aggregate level, following the benchmark case of Romer (1986). As a second assumption, the authors introduce a costly process of matching between workers and firms. In a first phase, the model simply displays in steady state endogenous growth with positive rate of unemployment. In a second phase, Keynesian features are introduced inside the model, assuming imperfect competition in the goods market. The model is enriched with many different parameters which can account for policy intervention.

The authors are particularly focused on the effect of changes in aggregate savings. They argue that unemployment can reduce the pool of savings and, subsequently, the investments necessary to enhance accumulation of capital. Departing from this observation, they use their model to investigate how different kinds of policy intervention can affect the endogenous variable through the mechanism described above ${ }^{\text {. }}$.

In the model a reduction of the hiring costs determines an increase in the number of vacancies created by firms. This enhances unemployment and generates an increase in the pool of savings, which stimulates accumulation of capital and enhances growth. In this case an intervention oriented to the labour market determines positive effect for both growth and unemployment. When the intervention is directed to increase the workers' bargaining power, the results are much more ambiguous. A higher wage discourages firms from opening new

\footnotetext{
${ }^{4}$ We will refer here to Caballero's comments to Bean and Pissarides (1993), which are enclosed at the end of their paper. Caballero summarizes the main results and presents some first considerations about the empirical evidence of the link between growth and unemployment.
} 
vacancies, increasing unemployment. On the other side higher income for workers turns into an increase in the pool of savings, which could stimulate growth. The net effect on the pool of savings cannot be determined a priori.

Adopting imperfect competition in the goods market, when the mark-up margin is sufficiently high, one observes that an increase of the marginal propensity to consume can increase the pool of savings and stimulate growth despite what could be predicted under Classical assumptions. The authors assume that hiring costs are valued in terms of consumption. If the price for consumption goods rises, hiring costs rise and unemployment also rises. A reduction in the propensity to save raises the employment level. In this case the effect is so strong that it also generates an increase in the pool of savings, enhancing growth through accumulation of capital.

This new framework by Bean and Pissarides (1993) can turn into an useful tool to investigate the impact of different policies on both the endogenous variables. The model is based on a wider set of assumption, such as expressing all the costs in terms of consumption and assuming standard conditions for determinacy of the steady state in the overlapping generation model. Of course results become more precise, but less robust.

\section{Workers on active search}

In the basic framework of the job-search model only firms are assumed to incur in a cost to match workers with their opened vacancies. Workers are just supposed to be passively waiting for a match, comparing their perspective income with the opportunity cost of being unemployed. King and Welling (1995), on the contrary, assume that workers need to bear a direct cost when they decide to actively search for a new job, while firms can create vacancies without any cost.

The authors develop a model where firms belonging to different spatial locations can receive different location-specific shocks. The firms are also affected by economy-wide exogenous technological progress. Under rational expectation hypothesis, workers find an incentive to move to high-productivity districts since they can increase their expected income in terms of wage. In steady state one finds that, in the presence of active cost of search for workers, the rate of search is an increasing function of the growth rate and total unemployment is a decreasing function of the growth rate.

This result allows us to show a different mechanism of determination of equilibrium unemployment. In both Pissarides (1990) and King and Welling (1995) there is a negative correlation between growth and unemployment, but in Pissarides (1990) the amount of search 
is decreasing with the size of innovations, since more vacancies are opened through the capitalization effect. In King and Welling (1995) the rate of search is increasing since workers try to move to more productive districts.

In the model the concept of "waiting-time unemployment" it is also introduced, and this occurs when the worker does not move, but just waits for an improvement of the condition of her/his own district. "Waiting-time unemployment", as well as total unemployment, is a decreasing function of the rate of growth.

The key assumption on which King and Welling (1995) derived their results is based on the presence of a direct cost for active search for workers that does not seem to find much support in literature. Nevertheless King and Welling (1995) show that the presence of asymmetry between the rational choice of workers and firms is a basic assumption for the result derived about the rate of search.

More, we find interesting the idea of developing the presence of spatially distinct locations affected by different shocks. The authors claim that this assumption can be even interpreted as the presence in the economy of different productive opportunities, to be matched with specific types of human capital by heterogeneous workers. The positive relation between the rate of search and the rate of growth could be interpreted as an incentive for workers to devote much time to human capital accumulation when the innovations are larger. This would imply that in periods of expansion there is less search within a profession and more switching between professions. We will develop this issue in the next sections.

\subsection{The neo-Schumpeterian approach to growth and unemployment}

Aghion and Howitt (1994) presented one first interesting reply to Pissarides' (1990) attempts to consider growth and unemployment in a joint way. They extended their basic model of creative destruction to take into account the problem of labour reallocation across the firms. A few years later further extensions have been brought to this model in their contribution on endogenous growth theory (See Aghion and Howitt (1998)).

Aghion's and Howitt's (1994) model is based on an economy constituted by a continuum of infinitely lived agents, indexed on the space $[0,1]$. Each household is endowed with a flow of one unit of labour service that s/he supplies to firms. S/he is also endowed with a stock of $h$ unities of human capital. All the households display the same preferences and the same intertemporal utility function over the final good $y$ :

$$
U(c)=E_{0} \int_{0}^{\infty} c_{t}\left(y_{t}\right) e^{-\rho t} d t
$$


The number of firms is endogenously determined in steady state. Aghion and Howitt define the firm as: "[...] an "institutional embodiment of knowledge", in other words [...] a research facilities for producing new knowledge, for generating new ideas." [Aghion and Howitt (1994), p.479].

Setting up a new plant requires a sunk cost $D_{t}$, which rises at the steady state growth rate: $D_{t}=D_{0} e^{\gamma}$. Once settled, each plant produces a stream of innovation, following a Poisson process of rate $\lambda$.

Production of the final good is performed combining a machine that embodies a specific technology, an appropriate worker to be matched with the machine and a variable amount of human capital:

$$
y_{t}=A_{t} f\left(h_{t}-h_{\min }\right)
$$

The function $f($.) displays all the neoclassical features and Inada conditions are assumed as well. In the basic framework the productivity parameter $A_{t}$ is exogenously determined and following the standard exponential rule: $A_{t}=A_{0} e^{-\gamma t}$. The Poisson process describes the flow of innovations for the firm. If a firm decides to convert the innovation project in new technology, it will afford an implementation $\operatorname{cost} C_{t}$ and the new process will be available at time $t$.

Unemployment is generated in the model by labour-reallocation across firms. In fact, as long as a firm does not innovate, it will not be able to cover its fixed cost and it will be forced to close forcing the worker into unemployment. The worker will start looking for a new match with another firm. The matching process is deterministic and it is described following a matching function of the type adopted by Diamond and Blanchard (1989) and Pissarides (1990). The matching function is assumed to display all the neoclassical standard features.

The recruitment rate $q(V)$ for a firm searching a new worker will be a decreasing function of the number of vacancies in the economy. For each worker looking for a new match the jobfinding rate $v$ will be an increasing function of the whole number of vacancies. Assume that the duration of each match takes $S$ unit of time. A worker forced into unemployment will wait $1 / v(V)$ units of time before finding a new job. On the other side a firm trying to associate a worker with a new machine, will wait $l / q(V)$ units of time before obtaining a proper match. Aghion and Howitt identify a situation of "involuntary unemployment" if workers spend more time looking for a job than working: $1 / v(V)>S$. Denoting by $u$ the rate of unemployment we can state the equilibrium condition for flows out to and into unemployment:

$$
(1-u)(1 / S)=v(V)
$$

If we assume $S$ constant and technologically determined, equation [2.2.3] can be re-written as:

$$
u=1-S v(V)
$$


This is a Beveridge curve, representing the typical negative relation between vacancies and unemployment. Aghion's and Howitt's main purpose consists on expressing the Beverdige curve in function of technological change. Through a progressive process of specification they nest growth generated by innovation into the labour market's steady state condition expressed by [2.2.4].

Whenever a firm decides to innovate, say at time $t_{0}$, it starts looking for a specialized worker. A match is obtained at time $t_{0}+1 / q(V)$ and the production process can begin.

The maximization condition for each firm is:

$$
\max _{h \geq h_{\min }}\left\{A_{t} f\left(h-h_{\min }\right)-p_{t} h\right\}=A_{t} \Pi\left(p_{t} / A_{t}\right)
$$

The price for human capital grows, as well as the other prices and costs, at the steady state rate: $p_{t}=p_{o} e^{\gamma}$. It follows that the firm needs to innovate to survive in the long-run. In fact, if the level of $A_{t}$ does not grow, the profit will decrease and finally falls to zero at time $t_{0}+S$, forcing the worker into unemployment.

If no innovations are introduced, at time $t_{0}+S$ human capital reaches a trigger value $p^{\max }$ which determines null profits for the firm. We can express the duration of a match in the following way:

$$
\begin{aligned}
& \frac{p_{t_{0}+S}}{A_{t}}=\frac{p_{t_{0}}}{A_{t}} e^{\gamma S}=p^{\max } \\
& S=\Gamma / \gamma \quad \Gamma=\log \left(p^{\max }\right)-\log \left(p_{t o} / A_{t}\right)>0
\end{aligned}
$$

Substituting equation [2.2.7] into equation [2.2.4] we obtain:

$$
u=1-\Gamma v(V) / \gamma
$$

This shows that growth generates a direct "creative destruction" effect on unemployment, acting through a reduction of the duration of the job match. Aghion and Howitt denote that other competing effects of growth on unemployment are to be taken into account. These effects work indirectly through the dynamic mechanism of entrance of new firms into the economy and through the clearing equation on the human capital market.

Consider the flow of discounted expected profits for a firm that is going to enter into the market:

$$
W_{t}=W A_{t}=E_{\varepsilon \geq 0}\left[\left(V_{t+\varepsilon}+W_{t+\varepsilon}\right) e^{-r \varepsilon}\right]
$$

Where $t+\varepsilon$ denotes the date of the first innovation for the firm which enters at $t$ and $V_{t+\varepsilon}=V A_{t+\varepsilon}$ is the present value of the stream of profits generated by the innovation occurred at $t+\varepsilon$. Solving equation [2.2.9] one obtains that:

$$
W=\lambda V /(r-\gamma)
$$


Denoting by $d$ the sunk cost the firm has to afford, the free-entry condition will be:

$$
d=\lambda V /(r-\gamma)
$$

Equation [2.2.5] represents the stream of profits that an innovation provides during the match $\left[t_{0}, t_{0}+S\right]$. As in Pissarides (1990), firms and market set the wage through a bargaining mechanism. Firms obtain a profit-share $\pi: 0 \leq \pi \leq 1$. Each match requires an implementation cost, denoted by $Z_{t}=z A_{t}$.

An innovation introduced at time a $t$, starts to generate profits at time $1+1 / q(V)$, when an appropriate match with a worker occurs. At this time the implementation cost is paid and the firm obtains a stream of profits lasting at time $1+1 / q(V)+S$. Considering what stated with equations [2.2.5], [2.2.6] and [2.2.7] we can finally express the discounted stream of profits generated by a firm:

$$
V=e^{-r / \tau}\left\{\pi \int_{0}^{\Gamma / \gamma} e^{-r / s} \Pi\left(p^{\max } e^{\gamma s-\Gamma}\right) d s-z\right\}
$$

obtaining a definitive formulation for the free-entry condition:

$$
d=\frac{\lambda}{r-\gamma} e^{-r / \tau}\left\{\pi \int_{0}^{\Gamma / \gamma} e^{-r / s} \Pi\left(p^{\max } e^{\gamma-\Gamma}\right) d s-z\right\}
$$

If the growth rate $\gamma$ increases two competing effects will emerge:

- It will decrease the net rate at which the stream of profits is discounted. For each firm the entry will result less costly. More vacancies will be created, reducing the unemployment rate. (Capitalisation effect).

- It will reduce the life-time of each firm (see equation [2.2.8]), by increasing the price for human capital. Each innovation will generate fewer vacancies than before. That will be reflected in an increase of the rate of unemployment. (Indirect creative destruction effect).

Considering equation [2.2.8] we can observe that creative destruction determines a direct negative effect on unemployment through the duration of each match and the parameter $\Gamma$. It also determines an indirect effect through the reduction of $V$, which lowers the job-finding rate $v(V)$.

To close the model we finally consider the clearing condition for human capital market:

$$
H=(1-u) \frac{1}{\Gamma} \int_{0}^{\Gamma} h\left(p^{\max } e^{\chi-\Gamma}\right) d \chi
$$

The left side represents the aggregate supply of human capital in the economy. The right side is the demand side, obtained by multiplying the labour force for the demand of human capital of each firm, where $\chi=\gamma s: \chi \in[0, \Gamma]$ is the technological age of the plant. From equation [2.2.14] 
we can deduce that $\Gamma$, maximum technological age for a plant is an increasing function of the rate of unemployment and a decreasing function of the aggregate stock of human capital in the economy.

The steady state for the system is a configuration $\left(u^{*}, V^{*}, \Gamma^{*}\right)$ that guarantee: clearing on human capital market, a constant unemployment rate, a constant number of vacancies, fixed at the level that sets to zero the profitability on the free-entry condition.

Differently parameterised simulations for the model reflected only two possible results: a reverse U-shaped relation between growth and unemployment or a monotone increasing relation between growth and unemployment. The presence of many parameters drives to a complex explanation of the effects of growth on unemployment, but simulations seemed to fit what happens in reality.

Aghion and Howitt extended their framework to account for flexible rate of interest, endogenous growth, and learning by doing. Endogenous growth was introduced adopting the results presented in Aghion and Howitt (1992). Learning by doing effects seem to be the most interesting feature of these new extensions.

Suppose introducing a learning mechanism, which depends on the level of workers employed in production:

$$
\gamma=\gamma_{0}+\alpha(1-u) \quad \alpha_{u}>0, \gamma>0
$$

The new definition for the rate of growth affects the free-entry condition expressed in [2.2.13]. The productivity of each match will depend on the constant rate of growth $\gamma_{0}$ and on the share of growth based upon the learning process. The final effect turns to be ambiguous.

An increase in unemployment determines an increase of the technological age of each machine $\Gamma$, as seen in the human capital market clearing equation. That increases the number of vacancies $V$ with a positive effect, reducing future unemployment. An increase in unemployment also determines an increase in the discount rate for the stream of expected profits and a reduction of learning-by-doing on each match. The latter effect occurs as long as less workers in active labour force generate less aggregate learning spillovers.

The authors assume that learning is a process that involves all the productive units, so that it does not generate creative destruction effects. An increase in the learning performance of households will not determine reallocation, but only unemployment reduction. On the other hand the learning process generates a feedback effect that might also generate strategic complementarities in the sense of Cooper and John (1988) and then multiple equilibria. The economy could be trapped in a situation of low growth, low learning and high-unemployment. 
The intervention of a planner would be required to move the system on a Pareto-preferred equilibrium.

In the earliest version of the model (see Aghion and Howitt (1998a)) the perfect substitutability hypothesis among intermediate good has been removed ${ }^{\text {E }}$ but nothing was told about the demand of final goods. The demand side of the model is reduced to a very simple problem of utility maximization, where the utility function is assumed to be linear. Consumers do not perform consumption-smoothing. More, households can be either employed or unemployed, but they are assumed to consume the same amount of good in each period. That is less likely to be true, as long as the same feedback effect that was presented for learning-by-doing can be experimented regarding the demand for the final good. Introducing a demand-side into the model could lead us to conclude that as long as less workers are in the active labour force, there will be less consumption and that will reduce the incentive to firms to enter and create new vacancies. Even in this case strategic complementarities could arise.

\subsection{Coordination failures, growth and unemployment}

Acemoglu (1997) criticizes the recent literature about the problem of growth and unemployment, pointing out that none of the contributions presented considers the problem of labour supply. Labour is carefully described in terms of demand, but not many considerations are spent regarding worker skills in relation to specific technologies. Acemoglu focuses on this aspect, presenting a model with two competing technologies and potential heterogeneity among workers endowed with different skills.

The first existing technology requires a fixed cost, normalized to 0 , while the second technology requires a new machine at the fixed cost $d>0$. The new machine needs to be matched with a skilled worker to produce a stream of productivity $y+\alpha$. Both the first technology and the second, if not properly matched with a skilled worker, produce a stream of productivity equal to $y$.

Suppose that the labour market allocation mechanism is described by a standard random matching function. If the proportion of skilled workers in the unemployment pool is $u_{\text {skill, }}$, the probability that a skilled worker will be matched with a vacancy will also be $u_{\text {skill }}$. Job-specific shocks occur at the exogenous rate $\lambda$, and determine the end of a match.

\footnotetext{
${ }^{5}$ Introducing imperfect substitutability to produce the final goods allows emphasizing the role of the capitalization effect. In fact, in a system with low degree of substitutability among intermediate goods an innovation that occurs in one sector will reflect positive effects in many other sectors and employment will rise. The creative destruction effect will be lower.
} 
Assume that the system is in steady state when the new technology becomes available. In any point in time each firm may decide about opening a new vacancy at flow cost $c$, adopting the new technology for production. Investing in the new technology, the firm may also choose whether to train an unskilled worker at $\operatorname{cost} \chi$. Assuming that $\theta$ represents the tightness on the labour market, the steady state condition at time $t=0$ is expressed by equation [2.1.3]. The value of a firm adopting a new technology with a filled job is denoted by $J^{N}$. The value is denoted $V^{N}$, when the vacancy is still available. Values $J^{0}$ and $V^{0}$ will denote the same quantities when the firm has not adopted the new technology. Let us now consider the following set of Bellman equations:

$$
\begin{aligned}
& r J^{N}-\dot{J}^{N}=y+\alpha-w^{N}+\lambda\left(V^{N}-J^{N}\right) \\
& r V^{N}-\dot{V}^{N}=-c+q(\theta)\left[\begin{array}{l}
\left(1-u_{\text {skill }}\right) \max \left\{J^{N}-V^{N}-\chi ; J^{O N}-V^{N}, 0\right\}+ \\
+u_{\text {skill }}\left(J^{N}-V^{N}\right)
\end{array}\right]
\end{aligned}
$$

Where $r$ is the fixed interest rate, the first equations state that the period value of a firm with a filled job is equal to the instantaneous capital gain $\dot{J}^{N}$, plus the net product $y+\alpha-w^{N}$, plus the opportunity cost of the stream of profit obtained in the case a job-specific shock occurs, expressed by $\lambda$. The second equation states that the period value of a firm with an open vacancy is equal to the instantaneous capital gain, minus the cost of opening a vacancy and plus a weighted average of the different profits the firm can earn if filling up the vacancy at probability $q(\theta)$. The worker matched with the firm can be skilled and so able to generate the stream of profits: $J^{N}-V^{N}$. In the case that the worker is unskilled, the firm will decide if it is worth it to train him, at the cost $\chi$, leaving him unskilled obtaining the stream of profits $J^{O N}-J^{N}$, or leaving the vacancy unfilled with a null profit.

A second set of Bellman equations describes similar conditions for a firm that does not adopt the new technology:

$$
\begin{aligned}
& r J^{0}-\dot{J}^{1}=y+\alpha-w^{0}+\lambda\left(V^{0}-J^{0}\right) \\
& r V^{0}-\dot{V}^{0}=-c+q(\theta)\left[\begin{array}{l}
\left(1-u_{\text {skill }}\right) \max \left\{J^{0}-V^{0} ; J^{N}-V^{0}-d-\chi\right\}+ \\
+u_{\text {skill }} \max \left\{J^{N O}-V^{0} ; J^{N}-V^{0}-d ; 0\right\}
\end{array}\right]
\end{aligned}
$$

Assume that: $m$ denotes the number of firms adopting the new technology, $n_{\text {skill }}^{0}$ the number of skilled workers employed in firms adopting the traditional technology, $n_{\text {unskill }}^{l}$ the number of unskilled workers employed in firms adopting the new technology. Acemoglu derives the 
dynamics for the pool of unemployed skilled workers, obtaining the following differential equation:

$$
\dot{u}_{\text {skill }}=\theta q(\theta)\left[m\left(1-n_{\text {unskill }}^{1}\right)+(1-m) n_{\text {skill }}^{0}-u_{\text {skill }}\right]
$$

Quantities $m$ and $n_{\text {unskill }}^{l}$ are determined by equations [2.3.1] and [2.3.2] and they consequently determine the flow of skilled workers into and out of unemployment.

Wages are settled through a Nash-bargain game, where workers are assumed to display a bargain power of $(1-\pi)$. No-arbitrage conditions are also assumed for equilibrium: $V^{0}=0, V^{N}=\delta$. Under the above assumptions from equation [2.3.1] and [2.3.2] we can obtain the following conditions:

$$
\begin{aligned}
& J^{N}(t)=[(1-\pi)(y+\alpha)+\lambda d] /[r+\lambda] \\
& J^{o}(t)=[(1-\pi) y] /[r+\lambda]
\end{aligned}
$$

A new technology is adopted when: $J^{N} \geq J^{0}+d+\chi$. This condition depends on the market tightness $\theta$ and can be re-written as:

$$
\alpha \geq \alpha^{l}\left(\theta_{0}\right) \equiv[r d+(r+\lambda) \chi] /(1-\beta)
$$

If the condition expressed in equation [2.3.5] holds, Acemoglu shows that the system will move towards an equilibrium where the new technology will be adopted progressively by all the firms and where firms will decide to train all the workers. The dynamics are determined through the market tightness $\theta$, which shifts from an initial value $\theta_{0}$ to a final value $\theta_{1}$, where $u\left(\theta_{0}\right) \geq u\left(\theta_{1}\right)$.

Acemoglu observes that a coordination failure could arise if we assume that each firm expects that no other firms will adopt the new technology. In this case one of the two no-arbitrage conditions does not hold any more $\left(V^{N} \neq d\right)$. Firms that loose their workers because of a random shock will not be able to sell the machine embodying the new technology. They will also expect no possibilities in finding a new skilled worker $\left(u_{\text {skill }}=0\right)$, since all the workers still will be still unskilled on the labour market. The new condition to invest in the innovative technology will be:

$$
\alpha \geq \alpha^{0}\left(\theta_{0}\right), \quad \text { where: } \alpha^{0}\left(\theta_{0}\right) \geq \alpha^{1}\left(\theta_{0}\right)
$$

The effective cost for investing in the new technology will be higher in respect to the case expressed by condition [2.3.5]. The author demonstrates that if $\alpha \in\left(\alpha^{l}\left(\theta_{0}\right), \alpha^{0}\left(\theta_{0}\right)\right)$ there will exist two pure strategy symmetric equilibria for this game between firms. In one equilibrium there will be no innovation and high unemployment, in the other equilibrium there will be innovation and lower unemployment. 
Expectations about the technology adopted by firms determines a kind of strategic complementarity which influences the actual rate of unemployment. This result is achieved within an intertemporal horizon model, where the relative frequency of skilled workers in the unemployment pool is dynamically upgraded over the time by equation [2.3.3]. This seems to suggest a way to introduce the static concept of Nash-equilibrium in a dynamic environment.

\section{The role of human capital}

In the previous section we presented some results already obtained to model unemployment in a growing economy. We now mean to explore alternative solutions to the problem, referring to the recent existing literature about growth. It is our purpose to show that some of the models and mechanisms adopted to describe the growth process display uncovered potentialities to provide an explanation for the persistence of unemployment in the economy.

We noted that the models based on Pissarides' framework are much more linked with the neoclassical conception of physical capital interpreted as the basic accumulating factor. A slightly different and interesting interpretation about the presence of heterogeneous skills can be found in the spatial model by King and Welling (1995), even if not deeply developed. The neo-Schumpeterian approach, on the other hand, assumes the presence of heterogeneous workers to be matched with different technologies, but the attention is focused on the decisional algorithm of the entrepreneur, leaving the workers to be passively waiting for a match. The process of match is hidden inside the "black box", represented by the matching function. In Acemoglu's (1997) framework, explicit consideration about the heterogeneity of the labour supply does not rely on a matching function, but the dynamics of the distribution of skills is still analysed as an aggregative result. The leading role is still assigned to firms that, in this case, strategically interact in the economy.

In this section we mean to focus on the role of human capital, devoting particular attention to the distribution of skills across the pool of workers. In our opinion, modelling this kind of heterogeneity among agents can turn into an interesting tool to analyse the relationship between growth and unemployment. The Endogenous growth revolution that occurred at the end of 19080s, gave a determinant contribution in this sense. In the neoclassical framework capital stock has traditionally been considered the most important cumulative factor. In spite of that a large number of endogenous growth models emphasized the features of the labour force. 


\section{$\underline{3.1 \text { Education and human capital }}$}

Following Lucas' (1988) re-exposition of human capital theory, some models have introduced new and more complex definitions of labour as a productive factor, finding that it could be assigned the leading role in the accumulation process. This fact can be very useful for our analysis if the distribution of the labour force can lead to a better explanation for the persistence of unemployment in a growing economy.

Lucas (1988) attributed to the workers a personal identity through the different endowment of human capital that they decide to cumulate before entering the process of production. This idea was not developed any further in his model and all the significant results were derived at the aggregative level.

Stokey (1991) followed Lucas' contribution, introducing a relation between heterogeneity of workers and heterogeneity of goods. Heterogeneity of workers is defined by Stokey in terms of different levels of human capital which they decide to cumulate before entering the process of production. Each agent sets the quantity of time to dedicate to education. The agent compares this investment with the opportunity cost of a higher wage during the time devoted to production. Investing time in education the agent unconsciously determines an increase of the aggregate stock of knowledge into the system. S/he is not able to take into account the external effect reflected in the whole economy, which is determinant to generate growth.

Heterogeneity of goods is defined by their technological intensities. Goods providing a higher number of Lancasterian characteristics are goods which require more specialized workers to be produced. The technology adopted consists of a CRS neoclassical production function, unchanging over time. Technological progress is defined in this framework as dropping lowerintensity goods and adding higher-intensity goods in the production set of the economy (see also Stokey $(1988))$. This process is generated by the external effect that allows improving technological skills and expanding the upper bounds of the production set. Stokey's main goal is providing an explanation for the leading role of international trade in determining different patterns of human capital specialization and goods production. To achieve this goal, Stokey removes the classical hypothesis of perfect substitutability among skilled and unskilled labour: skilled labour performs higher-quality services to produce technology-intensive goods displaying more characteristics.

Even if the main aim of Stokey's work is dealing with path dependence and international trade, we can underline some interesting features about the composition of the labour force. The

\footnotetext{
${ }^{6}$ In Stokey (1988) it is presented a formalization of this process, by which upper and lower bounds over the horizon of characteristics increase over the time. The bounds move in function of the level of knowledge previously cumulated inside the system.
} 
paper explicitly considers the problem of allocating heterogeneous workers over production of different goods. Removing the hypothesis of perfect substitutability among different workers we could infer a first cause of unemployment, which may arise in a context of growth. We can even think about this feature in a dynamic way. If international trade has a really strong influence on labour specialisation and productions it might happen that the distribution of workers across different lines of goods could be locked-in by international market mechanisms. Let us suppose that one country displays a high share of its output composition totally devoted to export. If an external shock affects the demand for the main set of goods produced by that country, unemployment could rise. In fact production could not be easily switched to different and more profitable goods as long as the distribution of workers is locked-in. The conclusions presented are just conjectures, derived by a simple framework built with different purposes, but they stress the importance of core assumptions, (like labour imperfect substitutability and labour and goods heterogeneity) that may be introduced to think about unemployment in a growing economy.

\subsection{Learning-by-doing and human capital}

The examples presented above interpret human capital as the result of investment in education. We will now consider another model developed by Lucas (1993). This framework collects Stokey's contributions about lock-in mechanisms and it matches them with a different formulation of sustained growth depending on allocation of labour across different lines of production ${ }^{\text {I }}$. In this case the main mechanism is not based on education, but on learning-bydoing.

Lucas defines an economy with a continuum of goods $x$, indexed by $s$, such that $s \in[0, S]$.

$$
x_{s, t}=A_{s} L_{s, t} h_{s, t}^{\alpha}
$$

Skilled labour $h L$ is the only factor of production. The level of accumulated skill is represented by $h$, where $\alpha$ expresses the effect of previously accumulated skill on the actual level of production. $A$ is a productivity parameter. Learning-by-doing is the leading process that allows cumulating skills over the time:

$$
\dot{h}_{s, t}=L_{s, t} h_{s, t}^{\alpha}
$$

At any point in time, the actual level of ability in producing the good $s$ depends on a starting level of knowledge referred to time $t_{0}$ and on the flow of workers who previously gave their contribution to the production of good $s$ :

\footnotetext{
${ }^{7}$ For another similar example, developed within a dynamic interpretation of the "big-push" mechanism of growth, see also Temple and Voth (1998).
} 


$$
h_{s, t}=\left[h_{s, t_{0}}^{1-\alpha}+(1-\alpha) \int_{t 0}^{t} L_{s}\left(v_{s}\right) d v_{s}\right]^{\frac{1}{1-\alpha}}
$$

At first we consider the learning process as developing independently over goods of different vintage. All the goods $x$, jointly considered, determine the aggregate production $y$ for the system:

$$
y=\int_{0}^{S_{t}} e^{\mu s} x_{s} d s
$$

$S$ defines the upper bound of the production set, while $e^{\mu s}$ represent the price coefficient for good s. Equations [3.2.1] and [3.2.3] imply:

$$
x_{s, t}=A_{s} L_{s}\left[h_{s, t_{0}}^{1-\alpha}+(1-\alpha) L_{s}\left(t-t_{0}\right)\right]^{\frac{\alpha}{1-\alpha}}
$$

At time $t$, the production of good $s$ depends on a preliminary level of knowledge and on the previous history in producing that good. To obtain sustained growth, Lucas assumes, at first, that the upper bound of the production set is exogenously augmented, following a Poisson process of rate $\lambda$ :

$$
S_{t}=\lambda t
$$

At this stage not many differences arise between Lucas' (1993) model and Stokey's (1991) model.

Stokey endogenizes the rate $\lambda$, assuming it dependent on average knowledge previously cumulated. Lucas (1993) still considers agents' heterogeneity, assuming that $\varphi$ is a density function with cdf $\phi$. This describes the distribution of workers across production of goods of different vintages. It follows that: $\forall s \in[0, \lambda t], L_{s, t}=\varphi(t-s / \lambda)$, where $L_{s, t}$ defines the number of workers devoted to produce goods of age $(t-s / \lambda)$. The remaining $1-\phi(t)$ workers produce a good over which no learning occurs. The same initial productivity is assumed for all goods and it is fixed at level: $h(s / \lambda, s)=\xi \geq 1$. One can now remove the hypothesis of independence of learning across goods and assume that $h_{s, t}$ denotes the experience accumulated in the whole economy for $s<S_{t}$. If the production of a good $s \geq S_{t}$ is started at time $\tau_{s}=s / \lambda$ (with $\tau_{s}=t$ ) we can assume that its starting level is proportional (in reason of $\theta$ ) in respect of the average skills previously accumulated:

$$
h_{s, \tau_{s}}=\theta \delta \int_{0}^{s} e^{-\delta(s-v)} h_{v, \tau_{s}} d v
$$

We can eventually infer that the ability required to produce the most sophisticated good at time $t$ follows a similar rule, such that:

$$
h_{S, t}=h(\theta, \delta, \varphi(v), \alpha)
$$


Assume that a new good will be effectively produced every time the previously accumulated ability reaches the trigger value $\xi \geq 1$. We can re-write equation [3.2.8] in the following ways:

$$
\begin{aligned}
& \xi=h(\theta, \delta \lambda, \varphi(v), \alpha) \\
& \lambda=\lambda(\underset{+}{\theta, \alpha, \varphi(v))}
\end{aligned}
$$

Equation [3.2.9] shows the relation that links the technological parameters of the model with the distribution of labour across different sectors. The trigger value of knowledge required for the introduction of a new good will be negatively related with the spillover parameter $\theta$, and with the learning parameter $\alpha$. If spillover and learning effects are high, it will be necessary that there exist a lower level of knowledge to start producing a new good. It is actually possible to change the perspective (see equation [3.2.10]) and regard $\lambda$ as the endogenous variable. The rate of introduction of new goods is increasing in respect of both the spillover and the learning parameters. It is also increased when the distribution of workers displays much of its density over the most sophisticated goods.

The relationship among these parameters and variables is pretty complex. Lucas assumes that the distribution of workers is steady and focuses his consideration to explain how "growth miracles" can happen, adopting a technology with learning-by-doing mechanism and continuous innovations. This kind of model is very interesting as long as it emphasizes the role of labour and human capital accumulation by learning-effects that generate dynamic returns on scale. New goods are introduced into the system. The mechanism which generates this process emerges by a self-feeding interaction between sectors (where $\alpha$ and $\theta$ are the parameters of interest) and the macroeconomic level, where $\lambda, \xi$ and $\varphi(v)$ determine the pattern of growth. For our main purposes we have to emphasize the fact that Lucas explicitly attributes an important role to the distribution of labour over the production of goods of different vintages. Considering the result derived in equations [3.2.9] and [3.2.10] we can infer that a good policy to obtain a higher growth rate in such a framework is giving incentives to employment; to concentrate on the production of more sophisticated goods. That would increase both learning effect and spillovers on $\lambda$. It would give acceleration to the system, lowering the trigger rate for introduction of more new goods. These considerations find a good justification especially dealing with international trade and lock-in mechanisms. But there is a risk which must be taken into account. If the policy-maker tries to specialise the process of production on goods of higher vintage, workers will be more and more specialised and less able to switch to different lines of production. If an external shock lowers the demand for high quality goods, the distribution of workers will be locked-in. This could determine a possible explanation for 
unemployment. In this case we might identify a trade-off between higher and faster growth with a totally unbalanced distribution of labour and lower growth with a balanced distribution of labour. Balancing the distribution of labour among sectors could be regarded as an irrational policy to achieve a Pareto-improvement for the growth path. In spite of that, the decision could be regarded as a good insurance against the risk of external shocks that can affect the foreign demand for higher quality goods. Moreover, this framework can represent an alternative way to model heterogeneity among workers.

\subsection{The role of distribution of human capital}

Galor and Tsiddon (1997) present a deeper analysis of human capital distribution, even formalized in its dynamic transition. They use an overlapping generation model defined in discrete time to show that human capital dynamics can evolve non-monotonically, determining path dependence.

In the model, agents produce a single good. In each period the good is used to be consumed, saved or invested in human capital. Production technology is described by a neoclassical CRS function:

$$
y_{t}=\lambda_{t} h_{t} f\left(k_{t}\right)
$$

The production function displays two inputs: human capital $h$ and physical capital $k$. The parameter $\lambda$ denotes the state of technology. In this framework technological progress is assumed to be labour augmenting. Production is performed in a competitive market and function $f(k)$ satisfies all the boundary conditions for an internal solution of the profitmaximizing problem. Denoted with $w$ and $r$ the wage rate and rate of return of capital respectively, first order conditions for the producer are:

$$
\begin{aligned}
& r_{t}=f^{\prime}\left(k_{t}\right) \\
& w_{t}=\lambda_{t}\left[f\left(k_{t}\right)-f^{\prime}\left(k_{t}\right) k_{t}\right] \equiv \lambda_{t} w\left(k_{t}\right)
\end{aligned}
$$

Assume that the world rental rate is a constant given: $r_{t}=r^{*}$, so that wage rate depends only on technological progress. At time $t+1$ the level of technology depends on the average level of human capital $h_{t}^{a}$ of the previous generation:

$$
\lambda_{t+1}=\max \left[\lambda\left(h_{t}^{a}\right), \lambda_{t}\right]
$$

The function $\lambda\left(h_{t}^{a}\right)$ is non-decreasing monotone and concave in the average level of human capital of the whole economy. In the first period of their life, agents invest an amount of real resources in human capital that will be devoted to production in the second period. Formally: an agent who was born at time $t$ to a parent belonging by dynasty $i$ inherits human capital $h_{t}^{i}$. 
S/he will invest $x_{t}^{i}$ units of real resource and one unit of labour in order to obtain $h_{t+1}^{i}$ of human capital.

$$
h_{t+1}^{i}=\phi\left(h_{t}^{i}, x_{t}^{i}\right)
$$

Equation [3.3.4] represents the technology that generates human capital. Function $\phi($.$) displays$ properties that determine the foundation of the theory:

1. Each individual's level of human capital is an increasing function of the parental level of human capital and of the investment in real resources devoted to its production.

2. There is complementarity between the two inputs of human capital production function.

3. There are diminishing returns on both inputs in the production of human capital.

Function $\phi$ captures the so called "home environment externality", as long as it states a link between the level of human capital of parents and children.

Parents also affect their children's level of human capital in an indirect way, through a "technological externality". This effect is registered by the function $\lambda\left(h_{t}^{a}\right)$. Through the labour augmenting technological progress, parents' average level of human capital affects the rate of return on investment in human capital for the child's generation. In this way parents stimulate further investment in human capital for the next generation.

Under proper assumptions for the function $\phi$, Galor and Tsiddon show that from equation [3.3.4]:

$$
x_{t}^{i}=\xi\left(h_{t}^{i}, \lambda_{t+1}\right)
$$

Investment in producing human capital is positively related to the parental level of previous the generation. From equation [3.3.3] we can also infer that investment in real resources is related with the average level of human capital of the previous generation. This double mechanism generates path dependence due to a "local home" externality.

Equations [3.3.4] and [3.3.5] can jointly describe the evolution of human capital within a dynasty:

$$
h_{t+1}^{i}=\phi\left(h_{t}^{i}, \xi\left(h_{t}^{i}, \lambda_{t+1}\right)\right) \equiv \psi\left(h_{t}^{i}, \lambda_{t+1}\right)
$$

While function $\phi$ displays the typical neoclassical behaviour, $\psi$ is a non-linear differential equation that may display a behaviour that is convex, concave one or even both. This result may lead to an interesting conclusion. In fact, even if the economy is described in a competitive environment and the ability is identically distributed across individuals, we register the presence of multiple steady states. In the long run polarization phenomena can arise in the distribution of human capital, allowing the existence of a steady state with different dynasties endowed with different levels of human capital. At this stage we have just focused on 
"local home externality" and we still suppose the technological progress to be steady. If we consider interaction between dynasties, the "global technology externality" should be taken into account as well. The authors consider the average level of human capital as a source to generate labour augmenting technological progress. Technological progress can be regarded as an upward shift of the function $\psi$ (.). In the long run that it eliminates the presence of a multiple steady state (see figure 1). In this steady state the distribution of human capital across dynasties converges to an unique level of equilibrium. Transitional dynamics are led by the technology bias of the wage rate, which induces to increase the optimal quantity of human capital to be accumulated by the agents.

Glaor's and Tsiddon's model was basically built to investigate the selection of the growth path as the result of human capital distribution. As a matter of fact, the authors devote special attention to the characteristics of the labour supply through a parental mechanism of transmission and technological change. This kind of approach is not very common in literature. Nevertheless, it can be related with the intuition that the process of job-matching can be influenced by endogenous determination of the labour supply. This might be an answer to the models presented in the previous section where the characteristics of the labour supply were substantially neglected.

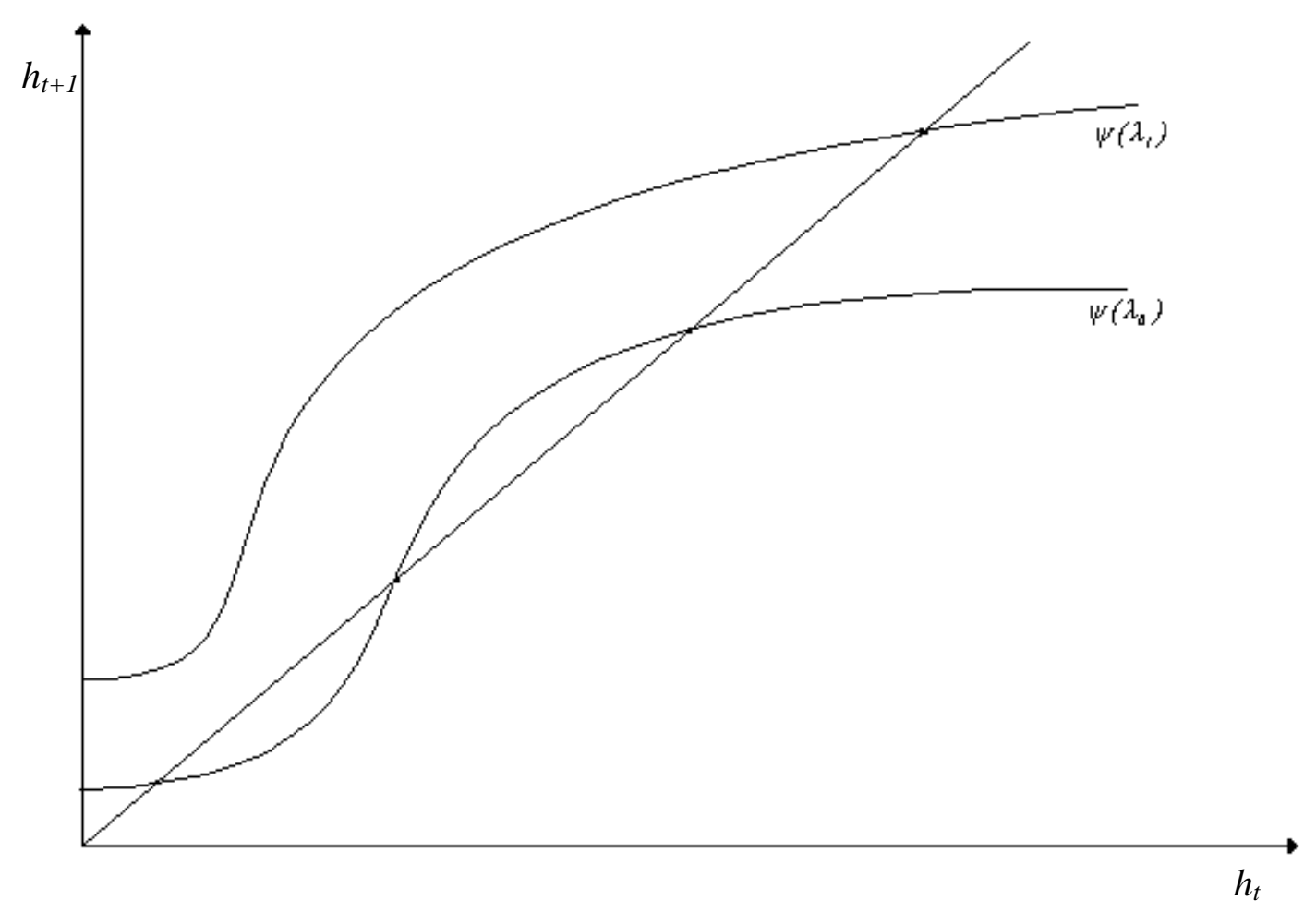

Figure 1: The effect of technological progress. 


\section{The role of complementarities}

\section{$\underline{4.1 \text { Complementarities amongst inputs and amongst processes }}$}

Endogenous growth theory emphasized the importance of definitions of factors that are involved in the process of growth. Descriptions of the production process became more complex, involving deeper degrees of microeconomic foundation, leaving the aggregative approach used in the past contributions. All these facts reflected on more accuracy devoted to the definition of the inputs. They also reflected on the description of a wider range of alternative ways to combine these inputs through technology. For the purpose of our search, this also means that we can actually dispose of a larger set of alternative and not mutually exclusive explanations and intuitions about the presence of mismatches of factors and, therefore, of unemployment.

For example, we have already noticed that capital has been considered in a broad definition and used as proxy for the level of social knowledge. Lucas (1988) distinguished skilled from unskilled labour. Stokey (1991) removed the substitutability in order to introduce some degree of heterogeneity among workers and subsequently among goods. In a more recent work, (see Stokey (1993)) she also presented a framework in which physical capital and unskilled labour are substitutes, while physical capital and skilled labour are complements. Goldin and Katz (1996) developed Stokey's contribution, building a model in which there are three competing technologies adopting three different factors (skilled labour, unskilled labour and capital). In their model it emerges that complementarity among capital and skilled labour is always present within the same technology, while this effect can be hidden in the first stage of transition from one technology to another. In phases of transition, the first impact of the new technology into the system generates an increase of demand for unskilled labour at the very beginning. When the new production process finally diffuses, it is followed by a subsequent increment in the demand for skilled labour.

Chari and Hopenayin (1991) consider the presence of complementarities developing a model of diffusion where human capital is specific to different technologies. The marginal product of the investment in a specific technology is assumed to be increasing in respect to the existing stock of human capital specific to that technology. In this way, old and new technologies are characterized by complementarities. The model is based on an infinite-horizon overlapping generations framework. Workers live two periods and they are unskilled in the first period of their life. Each agent acquires specific skills, through a process of learning-by-doing that induces a distribution of heterogeneous skills across different technologies for the next period. 
The distribution of human capital is endogenously determined by the choices of agents who invest in the first period of their life to earn benefits in the second period. The investment is irreversible, since the skill is specific for each vintage. The authors find that in steady state, (when the distribution of human capital is time-invariant), an increase in the exogenous rate of technological change shifts the distribution of skilled workers on the production of the most recent vintages. Chari and Hopenayin (1991) derive another interesting result, much more related with the purpose of our survey. They find that an increase in the rate of technological change not only speeds up the process of diffusion of new technologies, but it also lowers the amount of employees demanded by firms.

We introduce here another contribution by Young (1993a) which relies on the issue of complementarities and the dynamic allocation of labour. In his work he shows that the presence of complementarities can rise not only among factors, but also as the result of interaction among simultaneous processes, of invention and learning-by-doing.

Young observes that models led by learning-by-doing generally assume that the productivity's growing path is unbounded, as in Lucas (1988). This fact implies that technological progress should be regarded as a linear phenomenon, ignoring that history always displays cycles with intermittent phases of stagnation and growth. On the other hand R\&D models commonly assume that each occurring innovation drives all the previous technologies into obsolescence. Romer (1990), Grossman and Helpman (1991), Aghion and Howitt (1992) and many other contributions introduce that hypothesis.

Even in this case, Young moves an objection based upon historical considerations. In his opinion, technologies follow a more complicated cycle. When a new technology is introduced into the system setting-up costs are high and uncertainty about perspective results is also high: new ideas are unknown and not yet diffused. At the very beginning there are no facilities to help the diffusion of the innovating process and there are no experienced workers able to use the new technology without a proper training. In this early stage phenomena of complementarities between new and old technologies arise. It takes time to wait for the diffusion of the new technology to be sufficiently large. It is also necessary that enough workers can be matched with the new production process. Only at that point substitutability with the previous technology takes place.

To maintain a deeper degree of realism, Young (1993a) considers a framework where innovation and learning-by-doing are both present and binding each other.

More formally, he assumes that different goods are produced. Goods are indexed on the linear space $[0, N(t)]$, where $N(t)$ denotes the most sophisticated good. Labour is the only input of 
production. Stated that $s$ denotes the quality of a good and $t$ the time of production of that good, he defines the demand for labour $a(s, t)$ necessary to produce one unit of good:

$$
\begin{array}{ll}
a(s, t)=\bar{a} e^{-s} & \forall s \in[0, T(t)] \\
a(s, t)=\bar{a} e^{-T(t)} e^{s-T(t)} & \forall s \in[T(t), N(t]
\end{array}
$$

The term $\bar{a}$ denotes the upper bound for productivity's increments. That means that a certain level of labour will always be required to produce good $s$ and that also means that the learning process will extinguish at a certain point of time. Learning process occurs only on more sophisticated goods, as long as with the less sophisticated ones it has already been extinguished. The learning process also generates spillovers across sectors. This kind of phenomenon is a source of knowledge and improves the know-how to produce more efficiently. The variable $T(t)$ represents the dynamic bound for the learning frontier and it summarizes the social knowledge generated by the learning process. Assume that the function $L(s, t)$ accounts how many workers are employed at time $t$ over production of good $s$. We can define the following dynamic rule for index $T(t)$ :

$$
\dot{T}(t)=\int_{T(t)}^{N(t)} \psi L(s, t) d s
$$

where $\psi$ is the rate of learning for each worker. The stronger learning effect, the faster the index $T(t)$ will run towards more sophisticated good.

The system can even introduce new and more sophisticated goods through its R\&D sector. R\&D sector is characterized by free entry conditions and monopolistic competition. Firms own an infinitely lived patent for each new good they invent. Denote with $L_{r}$ the number of workers employed and with $\lambda$ the productivity of the $R \& D$ sector. The expansion of the production set can be expressed by the following rule:

$$
\dot{N}(t)=L_{r} / \lambda
$$

Different processes are actually inserted into the same framework. If it happens that $\dot{T}(t)=\dot{N}(t)$ the labour demand will be monotone downward sloping and the model will behave as if it was driven by a pure learning-by-doing process. On the other hand, if $\dot{T}(t)=0$, technological change will be generated by $R \& D$ sector only. Any intermediate case generates a situation in which learning-by-doing and $R \& D$ are mutually interconnected. In this case the labour demand is downward sloping on the space $[0, T(t))$ and upward sloping on the space $[T(t), N(t)]$. That is because with the most sophisticated goods, the learning process has just started and costs are high. It also reflects the fact that new technologies are generally less 
profitable in respect to older ones, in spite of the hypothesis of a linear obsolescence process. When the learning process generates enough knowledge, costs start to decrease and labour demand switches from upward sloping to downward sloping until it reaches its lowest bound $\bar{a} e^{-s}$.

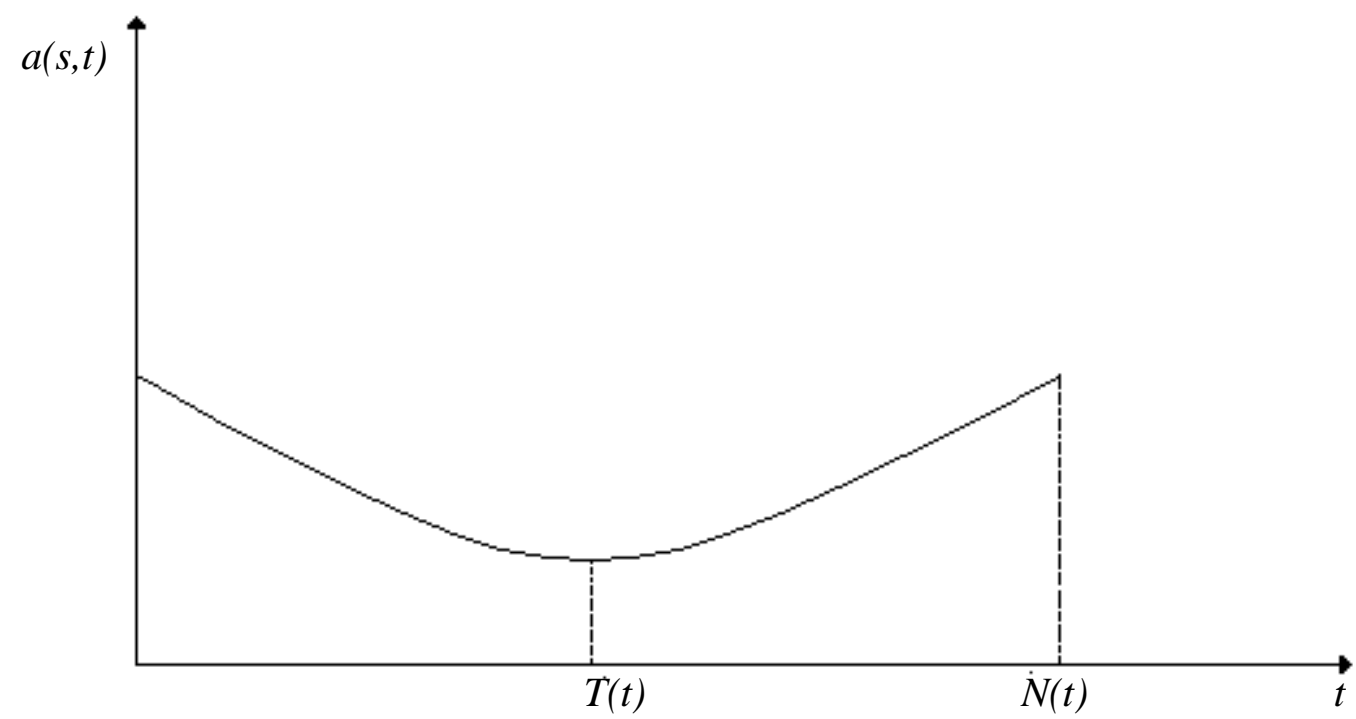

Figure 2: The labour demand over the time.

The connection between invention and learning-by-doing generates a particular shape for the labour demand. Even in this case, mismatches on the labour market could occur depending on the distribution of skills across the labour force.

\subsection{Strategic complementarities}

We noted that in Section II, one Acemoglu (1997), as well as one of the extensions of Aghion's and Howitt's (1994) model refer to the concepts of strategic complementarities and coordination failure. This approach registered increasing interest in the most recent literature.

The main results about the theory of strategic complementarities and co-ordination failure were presented by Cooper and John (1988). In their seminal work the authors claim that the role of expectations is determinant to identify causes of Pareto-inefficiency in the system. They formalized a flexible general Nash-equilibrium environment where agents interact strategically. A strategic complementarity is identified in this framework when an increment in strategy for a player $i$ determines an increment in the optimal strategy for a player $j \neq i$.

The main results derived by Cooper and John (1988) claim that the presence of strategic complementarities generates multiple equilibria in the system. Multiplicity of equilibria in itself is a sufficient condition for the presence of multiplier-effects. Cooper and John assume

\footnotetext{
${ }^{8}$ In this kind of formulation we are assuming symmetric spillovers across sectors.
} 
that "multiplier effects" are present when the aggregate response exceeds the individual response. More formally, indicated with $s_{j}^{*}$ the optimal strategy for agent $j$. Multiplier effects are present when the following inequality holds:

$$
\frac{d \sum s_{j}^{*}}{d \theta_{i}}>\frac{d s_{i}^{*}}{d \theta_{i}}>\frac{\partial s_{i}}{\partial \theta_{i}} \quad \text { for any } i, j \text { such that: } i \neq j
$$

The identification of a multiplier-effect represents the microeconomic explanation of a macroeconomic co-ordination failure, that can assume the form of an externality.

For this reason, this tool developed by Cooper and John has to be regarded as a powerful link between macroeconomic and microeconomic analysis. Often the identification of multipliereffects in a contest of strategical interaction still formalized in a static perspective. Its application in the field of Growth theory is not widely diffused.

Several contributions started to consider the role of expectations as another source of multiplicity of equilibria in models of growth. Path dependence does not only depend on the role of history, but it can be generated by interaction of the agents. (See for example Krugman (1991) and Adesrà and Ray (1998)). Developments in a dynamic environment and benchmarks models about the role of complementarities in macroeconomics can be found in Cooper (1999). More linked with the topic of our survey we remind the reader to Acemoglu $(1994,1996)$ and to Redding (1996).

\section{Discussion}

We found out that the main models of growth and unemployment display four basic features able to generate a link between the labour market and the growth mechanism. The first effect, identified by Pissarides (1990), is due to capitalisation. If the labour market is uncoordinated and costly to be accessed, competitive firms settled in a growing economy will try to maximize their discounted stream of profits, creating more vacancies each time the rate of growth increases in order to save higher hiring costs for the future. The second effect, introduced by Aghion and Howitt (1994), relies on Schumpeter's concept of creative destruction. It assumes that innovations introduce new technologies and drop old ones from the system, leading to labour re-allocations across the firms. If each job-match requires specific human capital for a specific vacancy, persistent unemployment may arise. The faster the rate of introduction of new technology, the shorter the period for each match.

In Pissarides (1990) and Aghion and Howitt (1994), the rate of growth was introduced as an exogenous variable, while in Bean and Pissarides (1994) both growth and unemployment are considered as endogenous variables. In this model the authors identify a third mechanism able 
to generate a link between growth and unemployment, which relies on the pool of savings of the labour force.

The fourth effect, mentioned in Aghion and Howitt (1994), is emphasized by Acemoglu (1997) and deals with the concept of strategic complementarities in the sense of Cooper and John (1988). This last mechanism describes the interaction among firms and workers that mutually influence their decisions about investing in new technology and accumulating human capital. Multiple equilibria may arise in this kind of framework and may possibly lead to unemployment stagnation traps.

Starting from these considerations we try to summarize some of the basic features about the issue of explaining unemployment in a growing economy, explicitly referring to the models and contributions we presented in the previous sections.

\section{Externalities, strategic complementarities and feedbacks}

In the models mentioned above the mechanisms described easily generate any sort of feedback, crossing externalities with agents' beliefs. The arrow of the growth-unemployment relation can be oriented in both directions and also generate recursive effects. Pissarides' models are focused on unemployment, introducing growth factors into the main framework of the jobsearch theory. Following Bean and Pissarides (1994), an example of feedback mechanism is due to a modification in the pool of savings. Unemployment generates a decrease in the size of the pool of savings that may slow down growth in a perfect competitive environment. A totally opposite effect may be obtained in the New Keynesian version of this framework, introducing the presence of an intermediate good sold in an imperfectly competitive market. In this set of models the arrow basically runs from unemployment to growth.

On the contrary, the neo-Schumpeterian analysis re-interprets the Beveridge relation, stressing the microfoundation of the determinants of growth, leading the arrow to run from growth to unemployment. Aghion and Howitt (1994), however, consider the presence of feedbacks occurring as the result of learning-by-doing. In this case they assume that the process of introduction of new technologies is sustained by learning-by-doing mechanisms. If unemployment rises, the fraction of active labour force that is actually on-learning gets smaller. The authors denote that feedbacks are not only sustained by externalities but that the role of expectations can generate other kinds of feedbacks. Aghion and Howitt (1994), as well as Acemoglu (1997), introduce them explicitly referring to the concept of strategic complementarities. This fact means that when unemployment is high entrepreneurs do not 
expect the average skill of workers to increase, so they neither innovate nor hire. In this way, unemployment rises and expectations of the agents are self-fulfilled.

Expectations can play a leading role in determining the pattern of growth. The authors mentioned above seem to suggest that a good explanation for the presence of unemployment in a growing economy can emerge combining many different kinds of inefficiency. Inefficiencies can emerge from technology changes not registered by the agents, but they can also emerge by coordination failures in the market, whenever agents take decisions simultaneously and their strategies generate multiplier effects at the macro-level. In this way one can compare different Pareto-ranked Nash-equilibria.

Dynamic perspectives of this kind of approach, based on expectations and interaction, are still very few though. We consider the stream of articles by Acemoglu $(1994,1996,1997)$ as an interesting contribution about that topic. Acemoglu (1997) eliminates the problem of a static approach based on Nash equilibrium and suggests adopting a system of Bellman's equations to represent the behaviour of heterogeneous agents over the time.

\section{Micro-founding growth and unemployment}

We have already had occasion to note that the neo-Schumpeterian approach displays a deeper degree of microeconomic foundation. Pissarides assumes that the outcomes of the matching function are an useful aggregate expression of what is generated at the microeconomic level by the mechanism of interaction among firms and workers. Starting from this observation, Pissarides claims that there is no need to introduce heterogeneity into the model, when a macroeconomic tool like the matching function works so good and is empirically corroborated. Fact is that each event of separation from job, which contributes to compose the stream of workers out of unemployment, is explained by the job-search theory as due to "firm-specific shocks". These shocks are generated by changes in technology and tastes, but they are not explained in detail. On the contrary Aghion and Howitt (1994) base their explanation for unemployment on differences among firms and among workers. Each worker is identified by her/his own knowledge and each firm is identified by its own technology. On the labour market the demand is determined by the technological level of firms and the supply is characterized by workers' level of human capital. In a normative perspective we find this kind of microfoundation of the Beveridge curve very useful. The Schumpeterian approach is based on the leading role of the entrepreneur in the process of growth. An accurate analysis of the entrepreneur's decisional algorithm allows us to show that job/vacancy mismatches can be determined by causes which lay far away from the labour market. In this environment growth 
and unemployment are completely joined and there is no point to think about policies for growth in the long run and policies for unemployment in the short run. We finally need to consider that when creative destruction and other kinds of feedback effects are present inside the system, a policy maker has to choose carefully the best way to enhance growth and lower unemployment, avoiding ambiguous results. A deeper degree of investigation represents a safer way to identify the right incentive which does not stimulate creative destruction and other negative feedbacks.

\section{Human capital and labour supply}

The majority of growth models usually consider labour supply inelastic or given. Attempts to endogenize the supply side of the labour market have been developed introducing a leisurewage trade-off into workers' utility function. We had occasion to note that in various frameworks of endogenous growth labour supply can even be considered from a skilltechnology perspective.

In our analysis of the neo-Schumpeterian approach we focused on the central role played by human capital, but we observe that while demand for skilled labour is analytically formalized, human capital supply is often treated in an aggregative way, like in Aghion Howitt (1994,1998). That is typical of the neo-Schumpeterian perspective, which follows the definition of human capital introduced by Nelson and Phelps (1966).

In our opinion the heterogeneous distribution of skills in the labour force, which characterizes the most recent models of growth, can represent one missing piece among the possible explanations for unemployment in a growing economy. For this reason we devoted more attention to different definitions of human capital and their way to be accumulated. We believe that the contributions of Lucas (1993) and Stokey (1991) about labour allocation among sectors and over products of different vintages, may provide some different and interesting developments about that issue. Galor and Tsiddon (1997) showed how the dynamics of human capital distribution across generations can determine different patterns of growth. This can represent another interesting way to extend previous results involving the problem of unemployment.

\section{Complementarities among factors, among processes and strategies}

Young (1993a) criticized another lack of the neo-Schumpeterian approach. Young (1993a) removes the hypothesis of immediate substitutability among old and new technologies, developing a framework in which learning by doing and $R \& D$ are concurrent engines of 
growth. Production of goods with different qualities is characterized by dynamic returns to scale that generates a U-shaped demand for labour. In a context of persistent unemployment this fact could represent another source of reflexion about possible ways to co-ordinate demand and supply on the labour market. In this case the slope of labour demand and its wideness over the production of different lines of goods depends on both the rate of learning and the rate of introduction of new goods.

Dealing with different and concurrent engines of growth still confirms that the causes for the persistence of unemployment in a growing economy can be identified analysing very different issues in the economic system that may lay far away from the labour market. The interplay of complementarity of factors, processes and strategies of the agents suggests a wide range of, and not mutually exclusive, explanations for unemployment in a growing economy.

\section{Conclusions}

We have presented in this paper the most recent literature about the persistence of unemployment in a growing economy. We have also tried to provide a first classification of the contributions which seem able to promote further studies about this issue. In this last decade the evolution of economic research allowed us to interpret the dynamics of the labour market, as well as growth, in a new perspective.

The renewed interest about the role of externalities, feedbacks, strategic complementarities and the interplay of different processes of accumulation (such as human capital and R\&D) led to drop assumptions like a neutral and disembodied technological progress. On the other side, the new tools that have been developed for the analysis of the labour market allowed us to explain long run unemployment in terms of differences among flows out of and into active labour force. This approach requires an increasing degree of microeconomic foundation of models. Very often it obtains the determination of multiple patterns of growth as a final result. If dynamic equilibria can be Pareto-ranked, the policy maker should try to select the best one, running opportune policies.

In this context the assumption of full employment may be more easily dropped from models of growth, in order to obtain a joint explanation of both growth and unemployment.

By the contributions considered in this paper it may be inferred that when growth and unemployment are matched in a unique framework, the causes of unemployment can be found far from the labour market. If we consider Aghion and Howitt's (1994) model, we can find out that policies for enhancing employment should be addressed to the firm. More attention should be dedicated to the role of the entrepreneur, trying to increase "capitalisation" effect of growth 
and trying to avoid the consequences of "creative destruction". Acemoglu (1997) finally shows us the relevance of interaction among heterogeneous agents and the interplay of a strategical behaviour which can lead to inefficient results and unemployment. Even in this case it emerges that different policies should be co-ordinated and addressed to both growth and unemployment at the same time.

\section{References}

Acemoglu D., (1994), "Search in the Labour Market, Incomplete Contracts and Growth", CEPR Discussion Paper, no.1026, Review of Economics Studies, forthcoming.

, (1996), “A Microfoundation for Increasing Returns in Human Capital Accumulation",

Quarterly Journal of Economics, 111, 779-804. $525-533$

(1997), “Technology, Unemployment and Efficiency”, European Economic Review, 41,

Adserà A., Ray D., (1998), "History and Coordination Failure”, Journal of Economic Growth, 3, 267-276.

Aghion P., Howitt P., (1998a), “Endogenous Growth Theory”, London, MIT press.

, (1998b), "Capital Accumulation and Innovation as Complementary Factors in LongRun Growth”, Journal of Economic Growth, 3, 111-30.

, (1994), "Growth and Unemployment", Review of Economic Studies, 61, 477-94.

51.

, (1992), “A Model of Growth Through Creative Destruction”, Econometrica, 60, 323 -

Akerlof G.A., Yellen J.L., (1986), “Efficiency Wage Models of the Labour Market”, Cambridge, university Press.

Arrow K., (1962), “The Economic Implications of Learning by Doing”, Review of Economic Studies, 29, 155-73.

Ashenfelter O.C., Layard R., (1986), "Handbook of Labour Economics”, Amsterdam, NorthHolland.

Barro R.J., Sala-i-Martin X., (1995), “Economic Growth”, New York, Mc Grow-Hill.

Bean C.R., (1994), "European Unemployment: A Survey", Journal of Economic Literature, 32, 573-619.

, Pissarides C., (1993), "Unemployment Consumption and Growth", European Economic Review, 37, 837-859. 
Blanchard O., Diamond P., (1989), "The Beveridge Curve", Brookings Papers on Economic Activity, 1, 1-76.

Cahuc P., Michel, P., (1996), "Minimum Wage Unemployment and Growth", European Economic Review, 40, 1463-1482.

Chari V., Hopenhayn H., (1991), "Vintage Human Capital, Growth, and the Diffusion of New Technology", Journal of Political Economy, 99, 6, 1142-1165.

, (1986), "Vintage Human Capital, Growth and Strucutural Unemployment", Working Paper no. 326, Federal Reserve Bank of Minneapolis, Minneapolis, MN.

Cooper R., (1999) “Coordination Games : complementarities and macroeconomics”, Cambridge University Press, Cambridge.

, John A., (1988), “Coordinating Coordination Failures in Keynesian Models”, Quarterly Journal of Economics, 53, 441-63.

Daveri F., Tabellini G., (2000), "Unemployment, Growth and Taxation in Industrial Countries", Economic Policy, 0, 30, 47-88.

Diamond P., (1965), "National Debt in a Neo-classical Growth Model", American Economic Review, 55, 1126-1150.

Domar E.D., (1947) ,"Expansion and Employment”, American Economic Review, 37,1, 34355, in: Domar E.D., (1957), "Essays in the Theory of Economic Growth", Oxford University Press, Oxford, 83-108.

Dunne T., Haltiwanger J., Troske K.R., (1996), “Technology and Jobs: Secular Changes and Cyclical Dynamics", NBER Working Papers Series, n.5656.

Eriksson C., (1997), "Is there a Trade-off Between Employment and Growth?", Oxford Economic Papers, 49, 1, 77-88.

Galor O., Tsiddon D., (1997), "The Distribution of Human Capital and Economic Growth", Journal of Economic Growth, 2, 93-124

Goldin C., Katz L.C., (1996), “The Origins of Technology-Skill Complementarity", NBER Working Paper Series, $n .5657$.

Gordon R., (1995), "Is There a Tradeoff Between Unemployment and Productivity Growth?", NBER Working Paper Series, n.5081.

Grossman G.M., Helpman H, (1994), "Endogenous Innovation in the Theory of Growth", Journal of Economic Perspectives, 8, 1, 23-44.

Harrod R.F., (1939), “An Essay in Dynamic Theory”, Economic Journal, in: Harrod R.F., (1972), "Economic Essays", London, MacMillan Economic Press, pag.256.

Jones C.I., Manuelli, (1997), "The Sources of Growth", Journal of Economic Dynamics and Control, 21,1, 75-114. 
, (1998), "Introduction to Economic Growth", London, W.W. Northon \& Co.

King. I, Welling L., (1995), "Search, Unemployment and Growth", Journal of Monetary Economics, 35, 499-507.

Krugman P., (1993), "Toward a Counter-Counterrevolution in Development Theory", Proceedings of the World Bank Annual Conference on Development Economics 1992. , (1991), "History versus Expectations”, The Quarterly Journal of Economics, 651-667.

Layard P.R., Nickell S.J., Jackman R., (1991), "Unemployment: Macroeconomic Performance and the Labour Market", Oxford, Oxford University Press.

Lucas R.E.Jr., (1993), “Making a Miracle”, Econometrica, 61, 2, 251-272.

, (1988), "On the Mechanics of Economic Development", Journal of Monetary Economics, 22, 3-42.

Nelson R., Winter S., (1982), "An Evolutionary Theory of Economic Change", London, Cambridge Mass. Belknap.

Nickell S., (1997), "Unemployment and Labor Market Rigidities: Europe versus North America", Journal of Economic Perspectives, 11, 55-74.

Phelps E.S., (1962), "The New of Investment: a Neoclassical Analysis", Quarterly Journal of Economics, 76, 4, 548-67.

Pissarides C.A., (2000), “Equilibrium Unemployment Theory”, Oxford, Blackwell. , (1990), "Equilibrium Unemployment Theory", Oxford, Blackwell.

Pugno M., (1998), "Crescita Economica e Disoccupazione: alcuni recenti sviluppi teorici”, Economia Politica, 15, 1, 119-65.

Redding S., (1996), "The Low Skill, Low-Quality Trap: Strategic Complementarities Between Human Capital and R\&D," Economic Journal, 106, 458-70.

Romer P., (1990), "Endogenous Technological Change", Journal of Political Economy, 98, 71102.

, (1987), "Crazy Explanations for the Productivity Slowdown", NBER Macroeconomics Annual, Cambridge MIT Press, 163-202. 1002-37.

, (1986), “Increasing Returns and Long-Run Growth”, Journal of Political Economy, 94,

Shapiro C., Stiglitz J.E., (1984), "Equilibrium Unemployment as a Worker Discipline Device”, The American Economic Review, 74, 433-444. 
Siebert H., (1997), "Labor Market Rigidities: at the Root of Unemployment in Europe", Journal of Economic Perspectives, 11, 37-54.

Solow R.M., (1994), "Perspectives on Growth Theory", Journal of Economic Perspectives, 1, $8,45-54$.

, (1969), "Investment and Technical Progress", in Arrow et.al., "Mathematical Methods in the Social Sciences", Stanford University Press.

, (1956), "A Contribution to the Theory of Economic Growth", Quarterly Journal of Economics, 70, 65-94.

Stiglitz J.E., (1976), "The Efficiency Wage Hypothesis, Surplus Labour, and the Distribution of Income in L.D.C.s.”, Oxford Economic Papers, 28, 185-207.

Stokey N.L., (1996), "Free Trade, Factor Returns, and Factor Accumulation”, Journal of Economic Growth, 1, 421-49.

, (1991), "Human Capital, Product Quality, and Growth", Quarterly Journal of Economics, 587-616. , (1988), "Learning by Doing and the Introduction of New Goods", Journal of Political Economy, 96, 4, 701-717.

Temple J., Voth H.J., (1998), "Human Capital, Equipment Investment, and Industrialization", Journal of Economic Dynamics and Control, 42, 1343-1362.

Van Schaik A.B.T.M., De Groot H.L.F., (1998), "Unemployment and Endogenous Growth", Labour, 12, 2, 189-219.

Young A., (1993a), "Invention and Bounded Learning by Doing", Journal of Political Economy, 101, 3, 443-472.

, (1993b), "Substitution and Complementarity in Endogenous Innovation", Quarterly Journal of Economics, 108, 775-807. 